\title{
- material manipulável em conversões entre representa- ções do número racional e suas implicações nos fenômenos de não congruência e heterogeneidade dos sentidos
}

\author{
Wellington José de Arruda \\ Melo (iD \\ Secretaria de Educação de \\ Recife/PE \\ Đwellingtonmelo74@gmail.com \\ Rosinalda Aurora de Melo \\ Teles \\ Universidade Federal de \\ Pernambuco \\ Ðrosinaldateles@yahoo.com.br
}

\author{
The manipulative in conversions between representations of \\ rational numbers and its implications in the phenomena of \\ variability of non-congruence and the non-reversibility
}

\begin{abstract}
This text is a cut of a research developed in Graduate Program in Mathematical and Technological Education, Federal University of Pernambuco (EDUMATEC-UFPE), whose objective was to investigate, in light of Raymond Duval Theory of Registers of Semiotic Representations, limits and possibilities in the use of manipulative in conversions between representations of rational numbers. A pilot experiment with four such materials integrated the methodological path and resulted in the choice of the Adapted Golden Bead Material for further analysis and the conclusion of the work. In this section, the focus will be on discussion of the implications of using this manipulative and the coding rule associated with it in the exercises of conversions between representations of rational numbers with regard to the phenomena of variability of non-congruence and the non-reversibility. The results of the research showed that the mediation of the Adapted Golden Bead Material reduced the difficulties caused by the change in direction and by the variation of congruence/non-congruence in the proposed conversions. The results also demonstrated that the application of the coding rule associated with the manipulable in the resolutive path can be applied to these conversions no matter what direction they are in.
\end{abstract}

Key words: Conversion; Congruence; Manipulative, Rational Numbers.

\begin{abstract}
Resumo
Este texto é um recorte da pesquisa desenvolvida no Programa de Pós Graduação em Educação Matemática e Tecnológica da Universidade Federal de Pernambuco (EDUMATEC-UFPE), cujo objetivo foi investigar, à luz da Teoria dos Registros de Representação Semiótica de Raymond Duval, limites e possibilidades no uso de material manipulável concreto em conversões entre representações de números racionais. Um experimento piloto, com a utilização de quatro materiais desse tipo, integrou o percurso metodológico e resultou na escolha do Material Dourado Adaptado para 0 aprofundamento da análise e a conclusão do trabalho. Neste recorte, o foco será a discussão das implicações da utilização desse material manipulável concreto e da regra de correspondência a ele associada nos exercícios de conversões entre representações semióticas do número racional no que concerne aos fenômenos de não congruência e heterogeneidade dos sentidos. Os resultados da pesquisa apontaram que a mediação do material dourado adaptado reduziu as dificuldades causadas pela mudança no sentido e pela variação de congruência e não-congruência nas conversões propostas. Demonstraram ainda que a aplicação da regra de codificação associada ao manipulável no caminho resolutivo pode ser aplicada a estas conversões não importando o sentido em que estejam.
\end{abstract}

Palavras-chave: Conversão; Congruência; Manipulável, Números Racionais. 


\section{INTRODUÇÃO}

O ensino e a aprendizagem dos números racionais continua sendo desafiante para docentes e discentes do ensino fundamental. Principalmente por apresentarem, em relação aos números naturais, especificidades que dificultam a compreensão dos estudantes e exigem dos professores o investimento em estratégias que possam fomentar uma apreensão significativa desse objeto matemático.

Em suas orientações didáticas, vinte anos atrás, os Parâmetros Curriculares Nacionais de Matemática já apontavam algumas especificidades dos números racionais em relação aos números naturais que geram dificuldades e tornam esse objeto de difícil compreensão para muitos alunos. Dentre elas, destacamos:

- Se o "tamanho" da escrita numérica, no caso dos naturais, é um bom indicador da ordem de grandeza (8345> 83), a comparação entre 2,3 e 2,125 já não obedece o mesmo critério;

- A comparação entre racionais: acostumados com a relação $3>2$, terão de compreender uma desigualdade que Ihes parece contraditória, ou seja, $1 / 3<1 / 2$;

- Cada número racional pode ser representado por diferentes (e infinitas) escritas fracionárias: por exemplo, $1 / 3,2 / 6,3 / 9,4 / 12, \ldots$ são diferentes representações de um mesmo número [1] (p. 101).

Tratando sobre tal distinção dos números racionais em relação aos números naturais, [5] (p. 4) observam que se trata de "uma característica que merece atenção por parte dos educadores matemáticos e precisa ser considerada no contexto do ensino e da aprendizagem como geradora de rupturas e continuidades, e também como fonte de dificuldades conceituais".

Por sua vez, a Teoria dos Registros de Representação Semiótica - TRRS, desenvolvida pelo pesquisador Raymond Duval, postula que devemos sempre considerar o trabalho com as várias representações de um mesmo objeto ao tratarmos sobre o processo de ensino-aprendizagem em matemática. Nesse sentido, a utilização dos variados tipos de registros de representação dos números racionais e a coordenação entre eles aparecem como exercícios fundamentais para uma eficaz apreensão desse objeto matemático [2]. A coordenação entre as diferentes representações do objeto matemático ocorre por tratamento, quando temos uma transformação acontecendo num mesmo tipo de registro, ou por conversão, quando na transformação ocorre a transição de um tipo de registro para outro [2].

Segundo a TRRS, muitas das dificuldades apresentadas pelos alunos estão relacionadas, principalmente, à sua capacidade de articular diferentes registros de representação. A atividade de conversão sempre exige um maior esforço cognitivo, mas é 
a partir desse exercício que o aluno adquire novos conhecimentos e consegue reconhecer aspectos conceituais e propriedades do objeto matemático que se tornam mais evidentes em cada um dos diferentes registros trabalhados [2].

Estudos em Educação Matemática frequentemente recomendam a utilização de materiais manipuláveis durante as aulas. [6] (p. 38) observam tais recursos "foram concebidos para serem manipulados pelos alunos. Só assim eles propiciam o início da construção dos conceitos e procedimentos básicos da matemática". [7] (p. 21) defende o material didático manipulável concreto como "um excelente catalizador para o aluno construir o seu saber matemático". [9] (p. 78) afirma que os materiais manipuláveis podem ser muito significativos "para auxiliar ao aluno na construção de seus conhecimentos".

A pesquisa intitulada "Conversões entre Representações de Números Racionais: limites e possibilidades no uso de material manipulável", desenvolvida no mestrado do Programa de Pós-Graduação em Educação Matemática e Tecnológica - EDUMATECUFPE buscou investigar a utilização do material manipulável nas conversões entre representações do número racional à luz da TRRS [8]. Nesse artigo, apresentamos um recorte dessa pesquisa com foco nas implicações do uso do material no que tange aos dois fenômenos relacionados ao exercício das conversões segundo Duval: não congruência e heterogeneidade dos sentidos [3].

\section{PRELIMINARES}

Os participantes do trabalho de pesquisa foram alunos do $8^{\circ}$ e $9^{\circ}$ anos do ensino fundamental. Os estudantes eram oriundos de escolas da rede pública municipal do Recife, capital do estado de Pernambuco.

Na primeira etapa do trabalho realizamos um experimento piloto utilizando quatro manipuláveis (disco de frações, régua numérica, pastilhas plásticas e material dourado adaptado). A partir dos resultados do experimento, decidimos concentrar nossa investigação no material manipulável com o qual os alunos obtiveram o maior índice de acertos no exercício das conversões entre as representações do número racional, a saber, o material dourado adaptado.

\subsection{Material Dourado Adaptado}

A médica e educadora italiana Maria Montessori realizou, no início do século $X X$, experiências e criou vários materiais manipuláveis destinados à aprendizagem de conteúdos matemáticos pelas crianças, entre os quais, o material dourado.

Os materiais desenvolvidos por Montessori eram comumente caracterizados pelo seu forte apelo à percepção visual e tátil. Isto se deve a convicção da educadora de que a aprendizagem derivava da ação dos aprendizes sobre os objetos. 
Em nossa pesquisa utilizamos o material dourado com algumas pequenas alterações que consistiram, basicamente, em marcações com pinturas de diferentes cores e inscrições de registros numéricos em sua superfície e, devido a tais alterações em sua estrutura original, acrescentamos, nesse texto, o termo 'adaptado' para designá-lo.

Compõem o material dourado adaptado três conjuntos de peças confeccionados em madeira, um para cada representação simbólico-numérica. Os conjuntos referentes às representações decimais e percentuais contêm, cada um, 1 placa, 5 barras e 10 cubos pequenos, já o conjunto das representações fracionárias, além de possuir 1 placa, 10 barras e 10 cubos pequenos, também é composto por subdivisões da placa em partes equivalentes a 1/2, 1/4 e 1/5.

As figuras 1, 2 e 3, destacam o conjunto vermelho, utilizado para elaborar as representações numéricas decimais do número racional, o conjunto verde para as representações numéricas percentuais e o conjunto amarelo para as representações numéricas fracionárias.

Figura 1: Conjunto vermelho

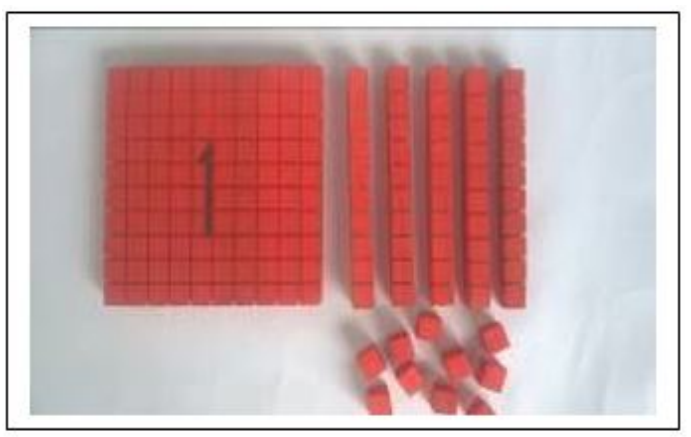

Fonte: [8]
Figura 2: Conjunto verde

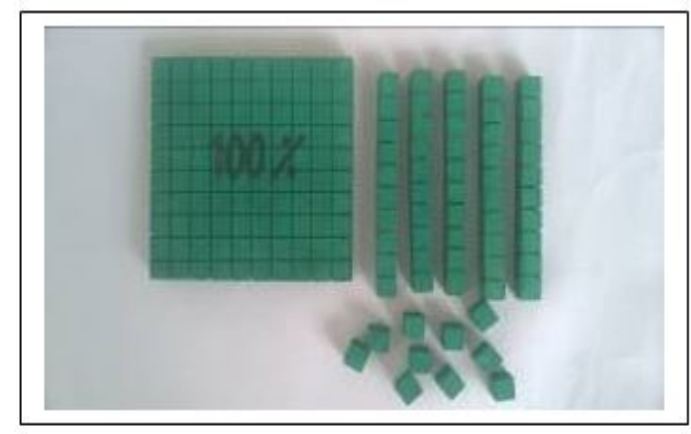

Fonte: [8]

Figura 3: Material dourado adaptado amarelo

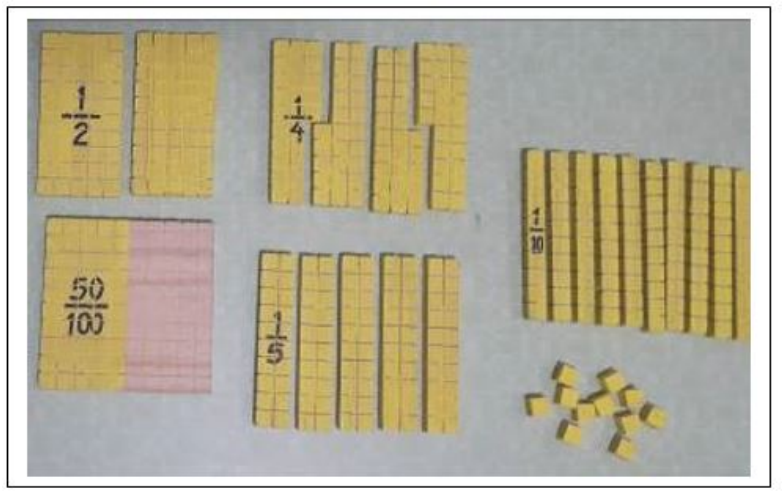

Fonte: [8]

No conjunto vermelho a placa representa o inteiro (1), as barras representam os décimos e os cubinhos representam os centésimos. De forma análoga, no conjunto 
verde, a placa representa o total (100\%) e as barras e cubinhos, respectivamente, $10 \%$ e $1 \%$.

O verso de cada placa traz registros numéricos relativos à metade, décima parte e centésima parte do todo para cada representação, como podemos ver nas figuras $4 \mathrm{e}$ 5:

Figura 4: Verso da placa do conjunto vermelho

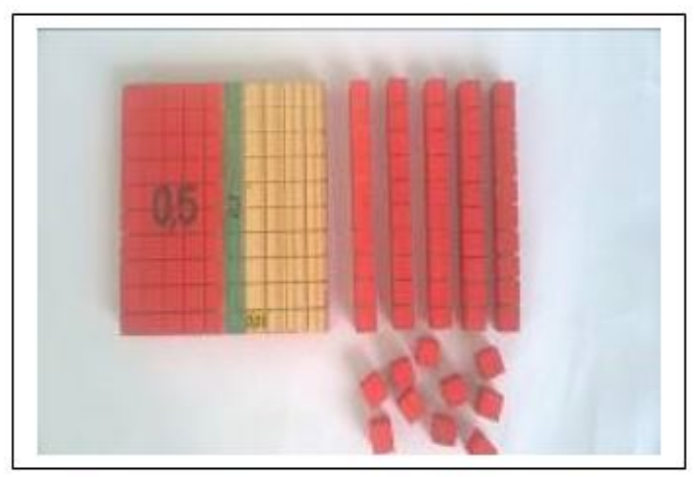

Fonte: [8]
Figura 5: Verso da placa do conjunto verde

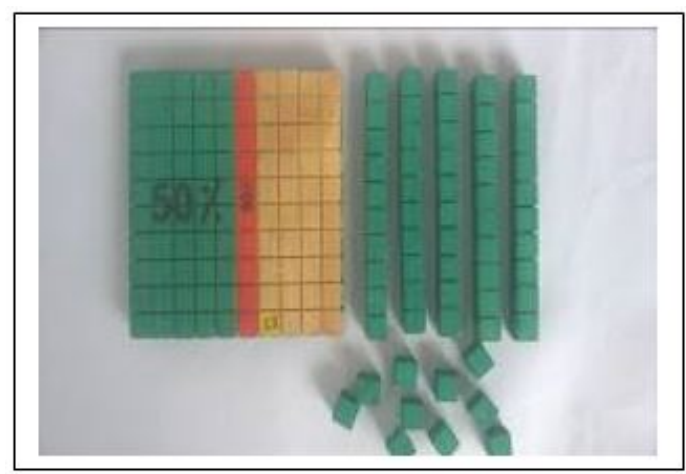

Fonte: [8]

O conjunto amarelo do material dourado adaptado, como se pode ver na figura 6 , tem uma placa inteira com o registro numérico fracionário 50/100 inscrito em sua metade, blocos menores representando 1/2, 1/4 e 1/5, além das barras e os cubinhos representando, respectivamente, as frações 1/10 e 1/100.

Figura 6: Representações fracionárias no conjunto amarelo

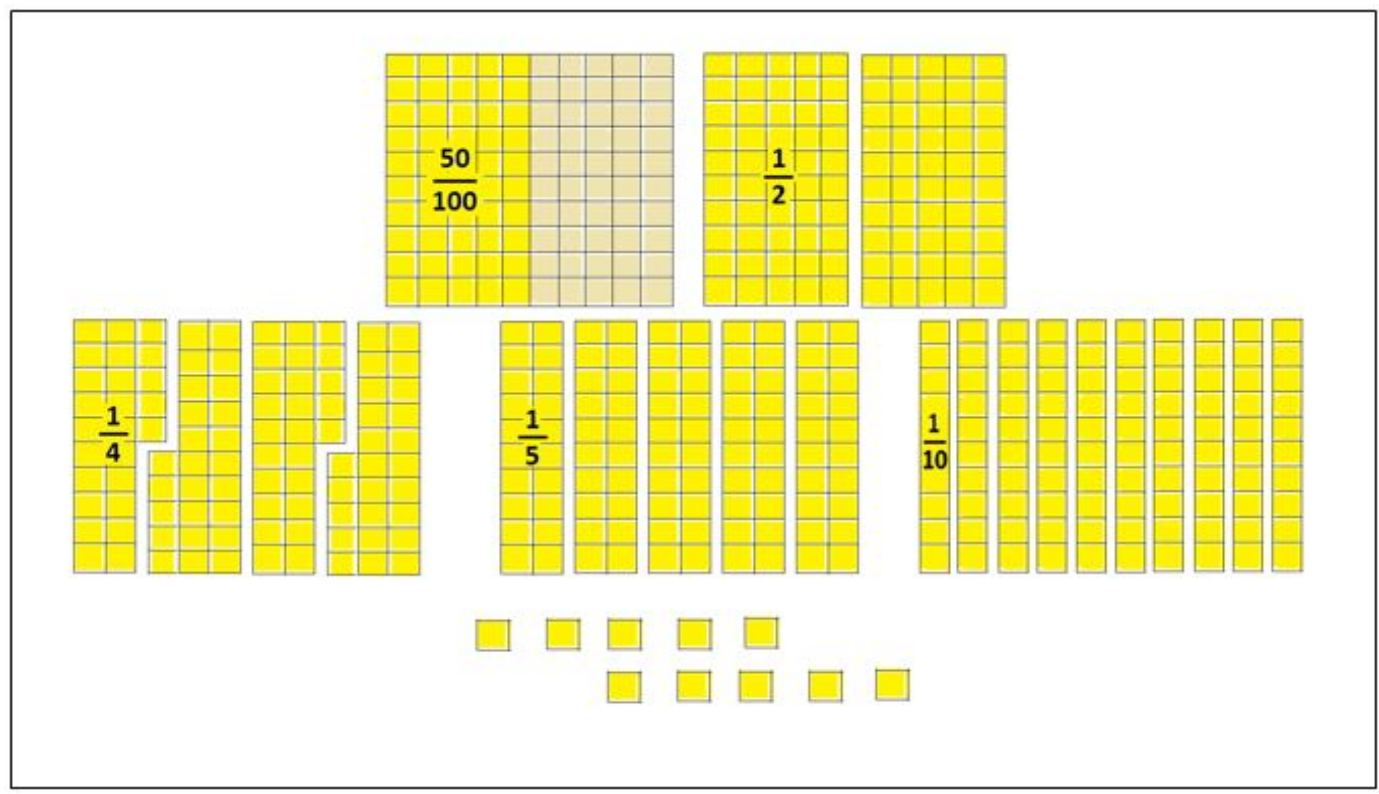

Fonte: [8]

Optamos por chamar de representações figurativas concretas as representações mistas elaboradas pelos alunos a partir do material dourado adaptado. Segundo 
[3] (p. 67), algumas representações semióticas podem ser classificadas como representações mistas, pois "resultam da superposição ou da fusão de dois tipos de representações". Nesse sentido, acreditamos que estas representações, aqui chamadas de figurativas concretas, podem ser também consideradas como um tipo de representação mista, já que, inscritas nas superfícies dos conjuntos vermelho, verde e amarelo, temos, respectivamente, os registros numéricos decimais, percentuais e fracionários.

O caminho resolutivo mais adotado pelos alunos, no experimento piloto, para realizar as conversões envolvendo representações simbólico-numéricas e figurativas do número racional está demonstrado no quadro 1 . Tomamos como exemplo a conversão da representação numérica fracionária $1 / 4$ para a sua representação numérica decimal:

Quadro 1: Possível caminho resolutivo com o material dourado adaptado para a conversão $1 / 4 \rightarrow 0,25$

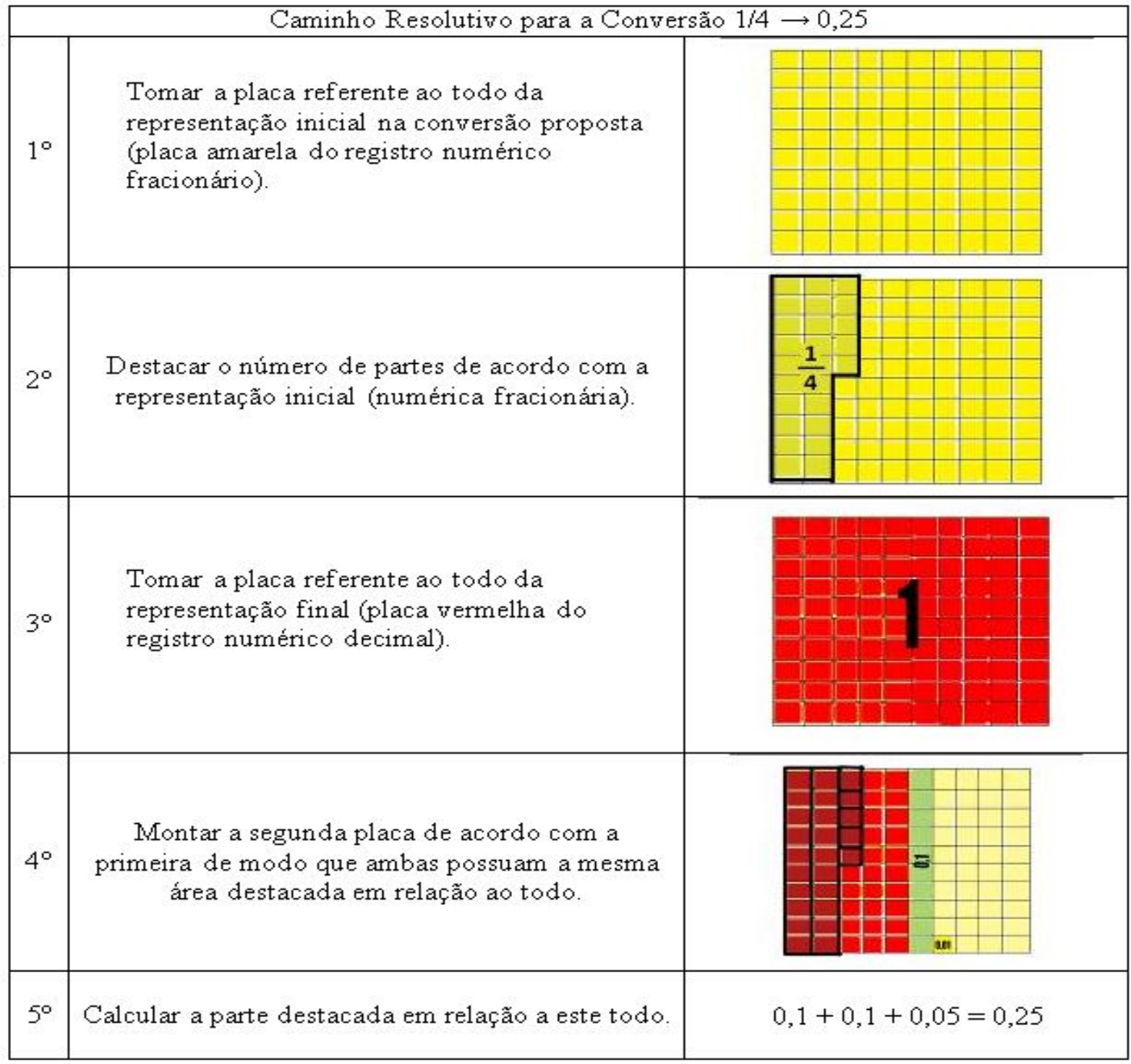

Fonte: [8] 
A estratégia de resolução consistia na utilização das duas placas referentes às representações envolvidas no exercício de conversão. No exemplo em questão, a primeira placa (conjunto amarelo) foi montada de acordo com o registro inicial (numérico fracionário) e a segunda placa (conjunto vermelho) manipulada de modo que a parte destacada tivesse a mesma área que a primeira em relação ao todo. Assegurada a equivalência das áreas, calculou-se, na segunda placa, a parte destacada em relação ao todo, tomando por referência as indicações numéricas gravadas no material (registro numérico percentual).

Nota-se que o procedimento resolutivo está baseado numa regra de correspondência associada ao próprio material, a saber, se placas de representações diferentes têm partes destacadas equivalentes, então tais partes representam o mesmo número racional.

Segundo [2], muitas vezes, as conversões são realizadas como tratamentos, ou seja, para converter a representação de um objeto de um registro a outro, aplicamse regras de correspondência e faz-se uma espécie de tradução. $O$ autor chama de codificação as conversões que resultam de aplicações diretas de regras de correspondência.

No quadro 2, apresentamos alguns exemplos de codificação, envolvendo dois objetos matemáticos, a função afim e a fração, bem como a regra de codificação relacionada:

Quadro 2: Exemplos de codificação nas conversões

\begin{tabular}{|c|c|c|}
\hline Registro A & Registro B & Regra de Codificação \\
\hline $\begin{array}{c}\text { Conjunto dos pontos cuja } \\
\text { ordenada é o dobro da } \\
\text { abscissa. }\end{array}$ & $\mathrm{Y}=2 \mathrm{X}$ & $\begin{array}{c}\text { Escrita literal de uma relação. } \\
\text { ponto é dado pelo par de } \\
\text { coordenadas (x,y) }\end{array}$ \\
\hline $\mathrm{Y}=\mathrm{X}$ & $4 / 6$ & $\begin{array}{c}\text { Dupla contagem: } \circ \\
\text { denominador refere-se a } \\
\text { quantas partes iguais o inteiro } \\
\text { foi dividido e o numerador a } \\
\text { quantas partes foram } \\
\text { destacadas. }\end{array}$ \\
\hline
\end{tabular}

Fonte: [8]

A codificação pode ser entendida, portanto, como um tipo de conversão muito limitada do ponto de vista cognitivo, pois não oportuniza aos estudantes o aprofundamento conceitual que uma conversão não condicionada a regras de correspondência oferece. 
A conversão tomada como simples codificação impede o que o autor chama de "uma apreensão global e qualitativa" [2] (p. 17).

\section{RESULTADOS PRINCIPAIS}

Aplicamos um instrumento avaliativo com 15 atividades de conversões entre representações semióticas do número racional para 10 estudantes dos anos finais do ensino fundamental ( $8^{\circ}$ e $9^{\circ}$ anos) e selecionamos, para a etapa seguinte, os 5 estudantes com os índices de acertos mais baixos.

Entre esses estudantes escolhidos para a sequência da pesquisa, somente um respondeu corretamente a questão 1 do instrumento avaliativo: 'Qual alternativa representa a fração 1/4 em número decimal: a) 0,41, b) 0,25, c) 0,14 ou d) 0,75?'

O desempenho na questão de número 7 também parece ser um bom exemplo da dificuldade desses estudantes frente algumas conversões. A pergunta era 'como podemos representar $1 / 2$ na forma percentual ?', as alternativas apresentadas eram: a) $20 \%$, b) $50 \%$, c) $21 \%$ e d) $12 \%$ e, outra vez, apenas um dos cinco estudantes assinalou a resposta correta.

Observou-se que, como não havia uma regra de correspondência ou codificação a ser aplicada, os estudantes não conseguiram passar da representação $1 / 2$ para a representação $50 \%$ demonstrando seu desconhecimento relativo a aspectos conceituais do objeto representado. A simples relação destes registros com a ideia de 'metade', por exemplo, já seria suficiente para tornar a conversão possível.

Em seguida, apresentamos aos estudantes o material dourado adaptado com sua forma de utilização, descrita anteriormente no 'quadro 1', e aplicamos o mesmo instrumento avaliativo. Dessa vez, os estudantes usaram o manipulável nas resoluções. $\mathrm{Na}$ 'tabela 1', temos os índices de acertos observados nestes dois momentos de avaliação:

Tabela 1: Índices de acertos dos estudantes

\begin{tabular}{|c|c|c|}
\hline Estudantes & Sem o manipulável & Com o manipulável \\
\hline A2 & $33 \%$ & $80 \%$ \\
\hline A3 & $47 \%$ & $87 \%$ \\
\hline A4 & $40 \%$ & $67 \%$ \\
\hline A5 & $33 \%$ & $87 \%$ \\
\hline A10 & $47 \%$ & $80 \%$ \\
\hline
\end{tabular}

Fonte: [8]

Os resultados parecem ratificar que os estudantes, embora sejam todos oriundos dos anos finais do ensino fundamental, apresentam sérias dificuldades quando estão diante de uma atividade de conversão. Sob a perspectiva da TRRS, tal dificuldade era previsível já que "a conversão das representações semióticas é a primeira fonte de 
dificuldade à compreensão em matemática" [4](p. 276).

Um dos fenômenos relacionados a conversão e que pode ser entendido como uma das maiores causas para tal dificuldade é a variação de congruência e não congruência. Para percebermos esse fenômeno, segundo [2], é suficiente compararmos a representação no registro de partida com a representação no registro de chegada. Para o autor

duas situações poderão ocorrer: Ou a representação terminal transparece na representação de saída e a conversão está próxima de uma situação de simples codificação - diz-se então que há congruência -, ou ela não transparece absolutamente e se dirá que ocorre a não-congruência [2] (p. 19).

Observa-se, portanto, que as regras de codificação surgem mais facilmente à medida que o grau de congruência nas conversões aumenta. No entanto, "os fenômenos de não congruência são mais numerosos que os fenômenos de congruência", o que explica a dificuldade dos estudantes em relação aos exercícios de conversão, por exemplo, entre representações do número racional [3] (p. 124).

[3] apresenta três critérios que permitem identificar se há congruência semântica na conversão proposta, são eles:

1 - Correspondência semântica entre as unidades de sentido das representações: para cada unidade de sentido no registro de partida, há uma unidade de sentido correspondente no registro de chegada.

2 - Unicidade semântica terminal: para cada unidade de sentido no registro de partida, só há uma única unidade de sentido correspondente no registro de chegada.

3 - Conservação da ordem das unidades de sentido: as unidades de sentido correspondentes nos dois registros seguem também a mesma ordem em ambas as representações.

Uma conversão cujas representações envolvidas atendem a estas três condições pode ser entendida como uma conversão de alto grau de congruência, enquanto que, nas conversões tidas como não-congruentes, tais condições deverão ser pouco ou nada observáveis [4].

Observou-se uma melhora significativa nos índices de acertos quando foi utilizado o material dourado adaptado para realizar as conversões, o que sugere uma influência positiva desse manipulável no desempenho dos estudantes, inclusive, em algumas conversões não congruentes. 
Podemos concluir que a utilização do manipulável e, consequentemente, da regra de correspondência a ele associada foi preponderante para o crescimento no número de acertos e, portanto, é preciso muita cautela ao considerarmos este êxito dos alunos, pois, segundo [2] (p. 27), "aquilo que de um ponto de vista matemático pode ser considerado um acerto (ou um erro) elementar não tem nenhum valor do ponto de vista cognitivo", em outras palavras, "um sucesso matemático não corresponde a um sucesso cognitivo".

Contudo, diante da "falta quase completa de regras" para realizar algumas conversões, sobretudo não congruentes, o manipulável mostrou-se capaz de romper com a imobilidade dos estudantes, oferecendo-Ihes um caminho resolutivo e colocando-os em movimento [4] (p. 285).

O outro fenômeno característico da conversão é que ao realizá-la observando um certo sentido dos registros o estudante não atesta ser capaz de fazê-la no sentido inverso, pois os dois sentidos de uma conversão são tão diferentes quanto "subir ou descer um caminho íngreme na montanha" [3] (p. 118).

Assim, nem sempre a conversão é realizada pelo estudante quando invertemos as representações nos registros de partida e chegada, pois "a conversão das representações, que não é uma codificação, é uma operação cognitivamente não reversível" [3] (p. 118). Essa heterogeneidade dos sentidos impede que ao exercitarmos a conversão num determinado sentido estejamos, a reboque, treinando a conversão no sentido inverso [2].

$\mathrm{Na}$ 'tabela 2', vemos que, na primeira aplicação do instrumento avaliativo (sem a utilização do manipulável), a dificuldade relacionada à heterogeneidade dos sentidos ficou bem evidente em algumas conversões. Já na segunda aplicação do instrumento avaliativo (com o material manipulável), os resultados sugeriram que a troca de sentido nestas conversões não trouxe maiores dificuldades aos estudantes:

Tabela 2: Percentual de acertos observados por sentido de conversão sem o manipulável e com o manipulável

\begin{tabular}{|c|c|c|}
\hline Conversão & $\begin{array}{c}\text { Acertos sem o } \\
\text { manipulável }\end{array}$ & $\begin{array}{c}\text { Acertos com o } \\
\text { manipulável }\end{array}$ \\
\hline Numérica fracionária $\rightarrow$ Numérica decimal & $40 \%$ & $100 \%$ \\
\hline Numérica decimal $\rightarrow$ Numérica fracionária & $90 \%$ & $100 \%$ \\
\hline Figurativa $\rightarrow$ Numérica fracionária & $100 \%$ & $100 \%$ \\
\hline Numérica fracionária $\rightarrow$ Figurativa & $90 \%$ & $100 \%$ \\
\hline Numérica percentual $\rightarrow$ Numérica fracionária & $90 \%$ & $100 \%$ \\
\hline Numérica fracionária $\rightarrow$ Numérica percentual & $20 \%$ & $100 \%$ \\
\hline Numérica decimal $\rightarrow$ Numérica percentual & $80 \%$ & $100 \%$ \\
\hline Numérica percentual $\rightarrow$ Numérica decimal & $30 \%$ & $100 \%$ \\
\hline
\end{tabular}

Fonte: arquivo da pesquisa 
Os percentuais de acertos dos estudantes demonstraram variações bem acentuadas a partir da mudança de sentido nas conversões sem a utilização do material dourado adaptado. A troca do tipo de registro da representação inicial pelo da representação final e vice-versa realçou as dificuldades advindas da heterogeneidade dos sentidos. Isto acontece porque o estudante não sabe como agir ao perceber que um certo método empregado com sucesso para realizar uma conversão entre representações perde sua aplicabilidade ao trocarmos o registro de partida pelo de chegada [3].

Com a utilização do manipulável, pudemos verificar uma não variação dos índices de acertos dos estudantes, o que pode sugerir uma redução das dificuldades produzidas pelas inversões no sentido das conversões a partir da aplicação do caminho resolutivo já apresentado no 'quadro 1'.

As observações a partir dos instrumentos avaliativos aplicados, tanto no experimento piloto quanto na etapa final da pesquisa, ratificaram que tais fenômenos inerentes ao exercício das conversões podem "criar um problema diante do qual o sujeito se sente desarmado e a possibilidade de conversão não vem mais à mente" [4] (p. 284).

No entanto, a utilização do manipulável ofereceu um caminho inicial e permitiu que estudantes que tiveram desempenho muito baixo nos exercícios sem o material dourado adaptado pudessem responder corretamente a maior parte das atividades com a sua inserção.

Os resultados indicaram que, a introdução do manipulável e, consequentemente, da regra de codificação a ele associada, implicou numa diminuição das dificuldades impostas pela mudança de sentido e variações de congruência e não-congruência nas conversões.

Percebeu-se que a mediação do material dourado adaptado pareceu atenuar os efeitos que tais fenômenos produzem nos estudantes. Isto pode ser explicado pela utilização da estratégia de resolução descrita no 'quadro 1' que pode ser aplicada a algumas conversões não congruentes qualquer que seja o sentido.

\section{CONSIDERAÇÕES FINAIS}

Neste artigo procuramos destacar os achados de nossa pesquisa com relação às implicações da utilização do manipulável no que concerne aos fenômenos característicos das atividades de conversão.

Verificou-se que a inserção do material manipulável no processo ensino-aprendizagem pôs os estudantes em movimento diante das conversões envolvendo representações semióticas do número racional nas tarefas propostas e foi importante para o aumento significativo dos índices de acertos. 
Vimos que a utilização do manipulável nas atividades de conversão ajudou os estudantes a superarem dificuldades de resolução que são oriundas da variação de congruência e não congruência e da heterogeneidade dos sentidos.

O material dourado adaptado contribuiu para explorar a pluralidade de representações no ensino, o que é importante para tornar acessível a percepção de outros elementos relacionados ao objeto matemático representado. Nenhuma representação isolada dá conta do todo do objeto, pois as representações são sempre parciais. Portanto, "é enganosa a ideia de que todos os registros de representações de um mesmo objeto tenham igual conteúdo ou que se deixem perceber uns nos outros" [2] (p. 31).

Nesse sentido, a utilização do material manipulável proporcionou a inclusão de um outro tipo de registro que, no âmbito desta pesquisa, chamamos de representações figurativas concretas. Tais representações, segundo a TRRS, impuseram "uma seleção de elementos significativos ou informacionais do conteúdo que representa" [4] (p. 280).

O uso do manipulável ofereceu um caminho inicial e permitiu que os estudantes, mesmo aqueles que obtiveram baixos índices de acertos nas conversões sem o material dourado adaptado, pudessem responder corretamente a maior parte das questões.

Observou-se, contudo, que o caminho resolutivo para realizar as conversões com o manipulável pareceu-nos baseado naquilo que [2] chamou de regra de correspondência ou codificação, o que do ponto de vista cognitivo não é muito promissor. Nesse sentido, a utilização de materiais manipuláveis nas conversões podem, por um lado, atenuar os efeitos produzidos pelos fenômenos inerentes à atividade da conversão e, por outro, estimular a codificação como recurso de resolução.

Observamos, porém, que a complexidade envolvida na montagem das placas e as observações proporcionadas pelas representações figurativas concretas podem justificar futuros estudos que visem a apontar também uma possível relevância de recursos dessa natureza no que concerne a apreensões conceituais dos objetos matemáticos estudados.

As representações figurativas concretas, como vimos no caso do material dourado adaptado, podem cumprir uma importante função enquanto representações auxiliares e, portanto, de transição, no exercício das conversões. Contudo, acreditamos que tal abordagem no ensino da matemática será bem sucedida se tais representações "são abandonadas pelos próprios alunos logo que eles compreendem, pois sua utilização Ihes parece um procedimento longo e custoso" [3] (p. 130).

Por fim, esperamos que o estudo empreendido possa contribuir para o enriquecimento da prática docente, sobretudo, no que tange à utilização de recursos dessa natureza durante as aulas de matemática. 


\section{REFERÊNCIAS}

[1] BRASIL. Secretaria de Educação Fundamental. Parâmetros curriculares nacionais: Matemática/Secretaria de Educação Fundamental. Brasília: MEC/SEF, 1998.

[2] R. Duval. Registros de representações semióticas e funcionamento cognitivo da compreensão em matemática. In: S. D. A. Machado. Aprendizagem em matemática: registros de representação semiótica. Campinas: Papirus, 2003, p.11-33.

[3] R. Duval. Ver e ensinar a matemática de outra forma: entrar no modo matemático de pensar os registros de representações semióticas. T.M.M. Campos (org.). Tradução de M.A. Dias. São Paulo: PROEM, 2011.

[4] R. Duval. Registros de representação semiótica e funcionamento cognitivo do pensamento. Revista Eletrônica de Educação Matemática - Revemat, Florianópolis, v.7, n.2, p. 266-297, 2012. [CrossRef] [Google Scholar]

[5] N. R. Fernandes et al. Número racional e seus diferentes significados. Anais do $2^{\circ}$ SIPEMAT, pp.122, 2008. Disponível em: http://www.gente.eti.br/lematec/CDS/SIPEMAT08/artigos/CO-134.pdf.

[6] V. Gitirana; J. Carvalho. A metodologia de ensino e aprendizagem nos livros didáticos de matemática. In: J.B.P.F de Carvalho (coord.), Coleção Explorando o Ensino, Matemática, v.17, Brasília: MEC/SEB, 2010.

[7] S. A. Lorenzato. Laboratório de ensino de matemática e materiais didático manipuláveis. In: S. A. Lorenzato. (org.). O Laboratório de ensino de matemática na formação de professores. Campinas: Autores Associados, 2006.

[8] W. J. A. Melo. Conversões entre representações de números racionais: limites e possibilidades no uso de material manipulável. Dissertação (Mestrado em Educação Matemática e Tecnológica) - Universidade Federal de Pernambuco. Recife, 2019.

[9] A. M. S. Turrioni. O laboratório de educação matemática na formação inicial de professores, dissertação de Mestrado, Universidade Estadual Paulista, Rio Claro, 2004.

\section{BREVE BIOGRAFIA}

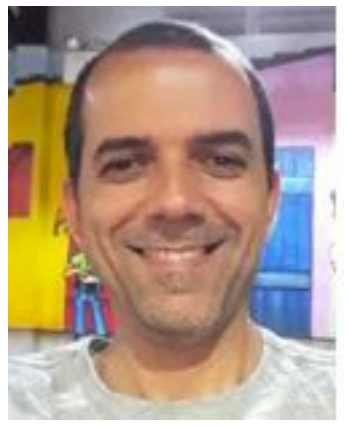

Wellington José de Arruda Melo (D) https://orcid.org/ 0000-0003-1071-8780

Mestre em Educação Matemática e Tecnológica pelo Programa de Pós-Graduação em Educação Matemática e Tecnológica (EDUMATEC) da Universidade Federal de Pernambuco. Professor da Rede Municipal de Ensino da cidade do Recife, Pernambuco.

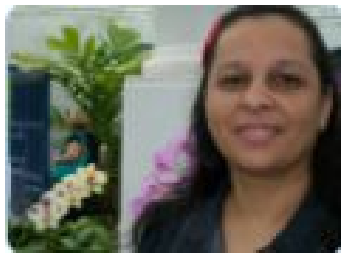

Rosinalda Aurora de Melo Teles (D) https://orcid.org/ 0000-0002-7289-3501

Doutora em Educação pela Universidade Federal de Pernambuco. Professora do Programa de Pós-Graduação em Educação Matemática e Tecnológica (EDUMATEC) da Universidade Federal de Pernambuco. 